American J. of Engineering and Applied Sciences 2 (1):171-175, 2009

ISSN 1941-7020

(C) 2009 Science Publications

\title{
Experimental Study of Flow Structures of Circular Pulsating Air Jet
}

\author{
${ }^{1}$ Rozli Zulkifli, ${ }^{2}$ Kamaruzzaman Sopian, ${ }^{1}$ Shahrir Abdullah and ${ }^{3}$ Mohd Sobri Takriff \\ ${ }^{1}$ Department of Mechanical and Materials Engineering, University Kebangsaan Malaysia, \\ 43600 Bangi, Selangor, Malaysia \\ ${ }^{2}$ Solar Energy Research Institute, University Kebangsaan Malaysia, 43600 Bangi, Selangor, Malaysia \\ ${ }^{3}$ Department of Chemical and Process Engineering, University Kebangsaan Malaysia, \\ 43600 Bangi, Selangor, Malaysia
}

\begin{abstract}
Problem Statement: Applications of impingement jets in industry for heating and cooling purposes requires a high convective heat transfer coefficient. Numerous studies have been conducted to improve the convective heat transfer coefficient for a steady impinging jet. A pulsating jet has a very high potential in replacing steady jet after it been found able to increase the heat transfer coefficients at certain pulsating frequencies. The objectives of this study were to; (i) determine the velocity profile of a circular pulsating air jet at different pulse frequencies and Reynolds Number using a rotating valve pulse jet system and (ii) to compare the normalized steady and pulsed jet velocity at highest Reynolds number of 32000 and highest pulsating frequency of $80 \mathrm{~Hz}$. Approach: Pulsation of the air jet was produced by a rotating cylinder valve mechanism at frequencies between $10-80 \mathrm{~Hz}$. Flow structures of the heated steady and pulse single circular axisymmetric air jet velocity were measured using a calibrated hot-wire anemometer and presented in non-dimensional form. The measurements were carried out at three different Reynolds numbers which was set at 16000, 23300 and 32000. The jet exit velocity profile for all the test frequency is determined by plotting the graph of radial distance against the non-dimensional jet exit velocity. Results: The corresponding Reynolds number in this test is based on time-averaged centerline velocity. The results of the velocity measurement were plotted side by side using non-dimensional parameters in order to make direct comparison of the velocity profile at different frequencies and Reynolds numbers. Stagnation point velocities are the same for steady and pulsating jet for all pulse frequencies. As the radial distance from the stagnation point increases, pulsating velocity increases between 20-30\% from radial distance of 2-22 mm. Conclusion: Results of the flow structures plotted show a distinctive exit air jet profile which can affect the impingement heat transfer characteristics. This was the result of enhanced turbulence intensity due to pulsating jet produced by the rotating cylinder. From the jet exit velocity profile obtained, it is found that mass flow rate for different test frequencies are slightly different due to the difference in the local velocity measurement affected by the pulses. The jet exit velocity profile data will be used to form a correlation between the pulsating jet velocity and heat transfer data.
\end{abstract}

Key words: Jet impingement, flow structure, pulsating hot air jet, Reynolds number, heat transfer coefficient

\section{INTRODUCTION}

High convective heat transfer coefficient is a very important factor that leads to numerous applications of impingement jets in industry for heating and cooling purposes. Applications of impinging air jets include the cooling of electronic equipment, aircraft engine nacelle and blade, drying of textiles, annealing of metals and tempering of glass. Extensive research has been conducted on steady impinging jet to understand their heat and mass transfer characteristics. Numerous studies and reviews on the subject of steady jet heat transfer have been published over the last several decades ${ }^{[1-3]}$. However, heat transfer in pulsating flows has been the subject of renewed interest in recent years since the present of flow pulsations has been found to increase the heat transfer coefficients.

Kataoka and Suguro ${ }^{[4]}$ show that stagnation point heat transfer for axisymmetric submerged jets is enhanced by the impingement of large-scale structures

Corresponding Author: Rozli Zulkifli, Department of Mechanical and Materials Engineering, University Kebangsaan Malaysia, 43600 Bangi, Selangor, Malaysia 
such as vortex rings on the boundary layer which occurred in pulse flow. Further tests carried out by Sailor et al. ${ }^{[5]}$ on the effect of duty cycle variation on heat transfer enhancement for an impinging air jet showed significant heat transfer enhancement. In this test, the effect of traditional variables such as jet to plate spacing, Reynolds number and pulse frequency were studied together with a new parameter, duty cycle representing the pulse cycle ON time to total cycle time. Duty cycle was shown to have a significant effect on the heat transfer enhancement.

Mladin and Zumbrunnen ${ }^{[6]}$ investigated theoretically the influence of pulse shape, frequency and amplitude on instantaneous and time-averaged convective heat transfer in a planar stagnation region using a detailed boundary layer model. They reported that there exists a threshold Strouhal number, St $>0.26$ below which no significant heat transfer enhancement was obtained. Results obtained by Zumbrunnen and $\mathrm{Aziz}^{[7]}$ on the effect of flow intermittency on convective heat transfer to a planar water jet impinging on a constant heat flux surface reinforces this finding. This experiment carried out at $\mathrm{St}>0.26$ found that local Nusselt number increases by up to $100 \%$. However, Sailor et al. ${ }^{[5]}$ used Strouhal number between 0.009 and 0.042 and still recorded significant enhancement in stagnation point heat transfer for pulse flow.

In order to study the heat transfer characteristics of an impinging pulse air jet, first the characteristics of a non-impinging pulse air jet needs to be understood. Farrington and Claunch ${ }^{[8]}$ carried out a test to determine the influence of flow pulsations on the flow structures of an unforced planar jet with $\operatorname{Re}=7200$ and $0<\mathrm{St}<0.324$. Results of the test were captured using infrared imaging and smoke-wire visualization. They concluded that for pulsating jets, the vortices were larger than those for the steady jet and occurred closer to the nozzle. These larger vortices resulted in an increased entrainment and led to a wider angle of the potential core. Jets with large amplitude of pulsations entrained surrounding fluid more rapidly and decayed more quickly than steady jets. An increase in turbulence intensity can be associated with the pulse decay.

In pulsed flows, the size and formation of coherent structures are influenced by the amplitude and frequency ${ }^{[6,9]}$. Large coherent flow structures can evolve from shear layers formed between a free jet flow and a surrounding fluid. The formation and interaction of flow structures can be influenced by the mixing within the boundary layer and a marked increase in turbulence intensities has been noted with pulse flows. Recent findings on the enhancement of heat transfer due to pulse air jets have encouraged new research in this subject. Comprehensive data showing the effect of pulse frequency on local and average heat transfer profile are still limited and there is need of further investigation.

The purpose of the first part of this study is to investigate steady and pulsating single circular air jet flow structures. The same test setup will be used to measure the heat transfer coefficient and Nusselt number in order to understand the heat transfer characteristics of a pulsating air jet. Comparisons between steady and pulsed jet heat transfer was discussed in details together with other published results.

\section{MATERIALS AND METHODS}

Pulse flow system: Figure 1 shows a schematic diagram and photo of the rotating valve pulse jet system. The pressurized air used in the experiment is supplied through the compressor. The air is continuously fed through a permanent piping to the heating chamber and the nozzle. The supply pipe of the air storage compressor tank is controlled by a stop valve. A pressure regulator was placed in between the air heater and the stop valve to regulate the supply of air. A vortex flow meter is placed just downstream of the pressure regulator and is used to measure the mass flow of the air jet impinging on the surface of the plate. An air heater is used to heat the air jet with an associated max air temperature of $60^{\circ} \mathrm{C}$.

The pulse air jet is generated using a rotating cylinder valve driven by an electric motor controlled by an electronic motor controller. The system consists of a rotating cylinder enclosed inside a block aluminum alloy body. A $20 \mathrm{~mm}$ diameter hole was bored in the rotating cylinder normal to its axis to allow air passage. The aluminum alloy body is fixed to the supporting shaft and has a $40.2 \mathrm{~mm}$ hole diameter bored through its center. The cylindrical rotating has a diameter of $40 \mathrm{~mm}$ and it was aligned inside the body such that a $0.1 \mathrm{~mm}$ radial clearance is achieved between the stationary body and the cylindrical valve. This led to minimal leakage through the gap with the valve is in the closed position.
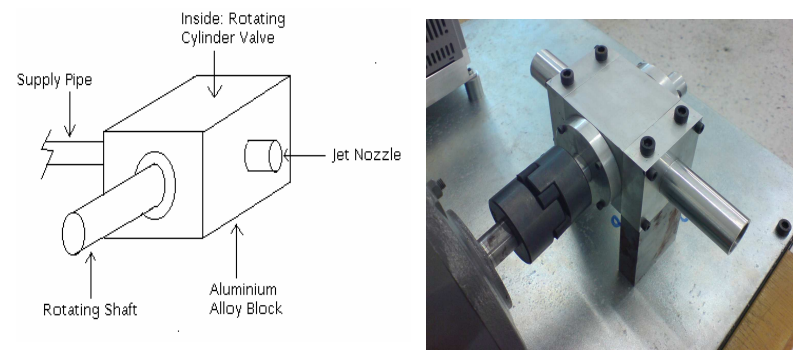

Fig. 1: Schematic diagram and photo of the rotating cylinder valve pulse jet system 
The $15 \mathrm{~mm}$ diameter shafts at each end of the rotating valve were press-fits on sealed bearings to prevent air leakage through the shafts when the valve is closed. A $20 \mathrm{~mm}$ diameter hole was bored on each side of the aluminum block and the hole was aligned with the hole through the rotating cylinder. One end of the bored hole was connected to the compressed storage air tank and the other end was connected to the jet nozzle. In the tests, a jet nozzle of $20 \mathrm{~mm}$ diameter and length of $50 \mathrm{~mm}$ was used. Figure 2 shows the schematic diagram of the experimental test set-up.

The system can produce a maximum operating frequency of $80 \mathrm{~Hz}$. The tests were carried out for both continuous and pulse jet flow. The Data Acquisition System was used to record the jet exit velocity and the temperatures on the impingement plate surface. Heat transfer coefficients were calculated from the value of temperature drop between the jet exit air and the plate surface.

Pulse flow measurement: Time-averaged velocity of the centreline jet exit air close to the nozzle was measured with a calibrated hot wire anemometer. Straight probes are mounted with the probe axis parallel with the dominant velocity direction. The probe is mounted in a probe support, which is equipped with a cable and BNC connector, one for each sensor on the probe. The probe bodies and the probe support are designed so that their outer surfaces are electrically insulated from the electrical circuitry of the probe or anemometer circuit. They can therefore be mounted directly to any metal part of the test rig without the risk of ground loops. The distance between the probe and the CTA is kept as small as possible. The standard cable length used is 4 meters probe cable plus 1 meter support cable. The traverse system is used to move the probe around in the flow. The anemometer selected for use in this setup is made by Dantec Dynamics, Inc.

The time-averaged centreline velocity was used for calculating the nominal Reynolds numbers. Due to the high pulsation frequency, the data were recorded at a sampling frequency of $1 \mathrm{kHz}$. Figure 3 shows the velocity profile at pulsation frequency of 10 and $20 \mathrm{~Hz}$ for a jet nozzle diameter of $20 \mathrm{~mm}$. The ON part of the pulsation duty cycle has velocity variation similar to a half-cycle of a sinusoid and the velocity at the nozzle exit is close to zero during the nominally OFF part of the duty cycle. This shows minimal air leakage in contrast with the work carried out by Azevedo et al. ${ }^{[10]}$ where the leakage is quite significant. The stable flow structure created from the experiment is important in order to correctly measure the instantaneous heat transfer.

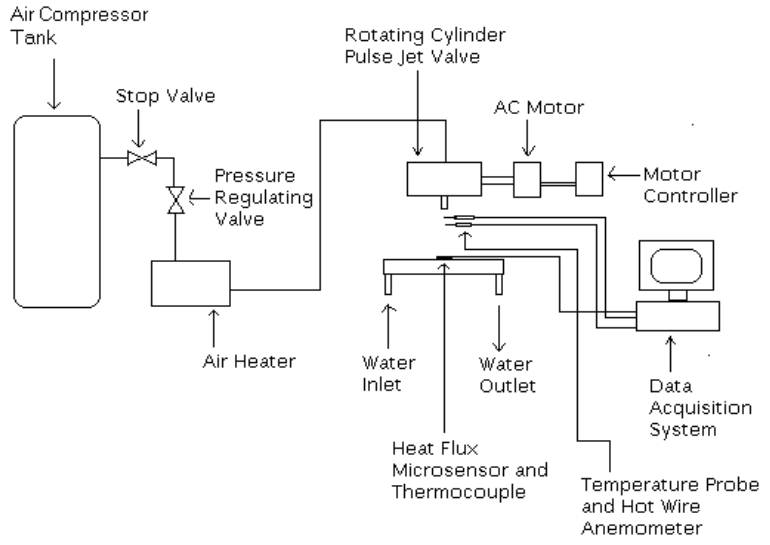

Fig. 2: Schematic diagram of the experimental test setup
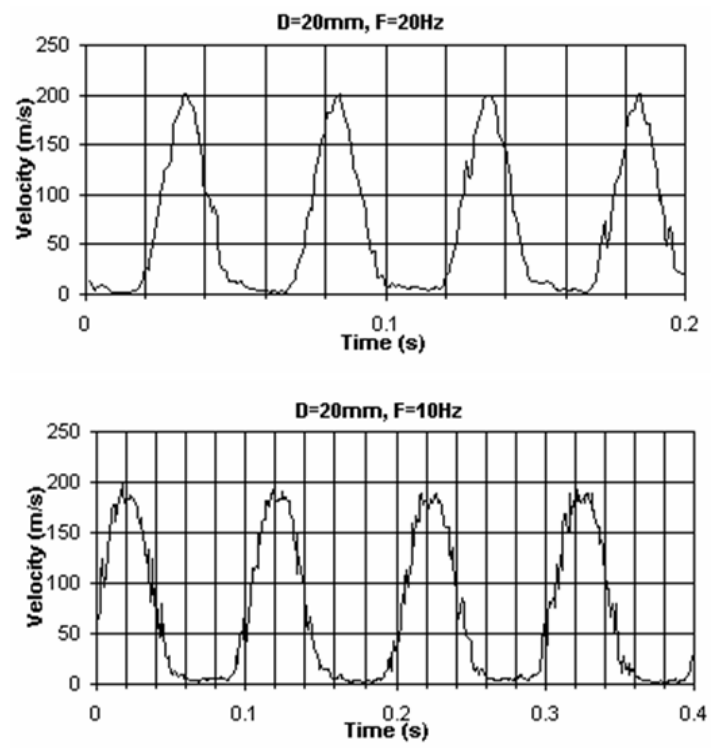

Fig. 3: Velocity Profile for Pulsation Frequencies of 10 and $20 \mathrm{~Hz}$

The jet exit velocity profile for all the test frequency is determined by plotting the graph of radial distance against the non-dimensional jet exit velocity. The corresponding Reynolds number in this test is based on time-averaged centreline velocity. From the jet exit velocity profile obtained, it is found that mass flow rate for different test frequencies are slightly different due to the difference in the local velocity measurement affected by the pulses. The average mass flow rate based on the local jet exit velocity difference was calculated by numerically integrating the local mass flow rate measurement over the nozzle area. The Reynolds Number based on average mass flow rate for each test frequencies are then determined using Eq. 1 (Brown 1999) below: 


$$
\operatorname{Re}=\frac{w D}{A_{\text {hole }} n u}
$$

Where:

$\mathrm{w}=$ The average mass flow rate calculated from the jet exit velocity profile

$\mathrm{D}=$ The nozzle diameter

$\mathrm{A}=$ The nozzle area and $\mathrm{m}$ is the dynamic viscosity of air at supply air temperature.

\section{RESULTS}

Results presented in this study are the profiles of high pressurized air exiting a mechanically rotating cylinder at different frequencies. Figure 4 shows the comparative radial velocity between steady and pulse jet flow for Reynolds number 16,000 and Frequency of $40 \mathrm{~Hz}$. Figure 5-7 shows the non-dimensional jet exit velocity profile for steady and pulse flow for Reynolds Number, $\operatorname{Re}=16000,23300$ and 32000 .

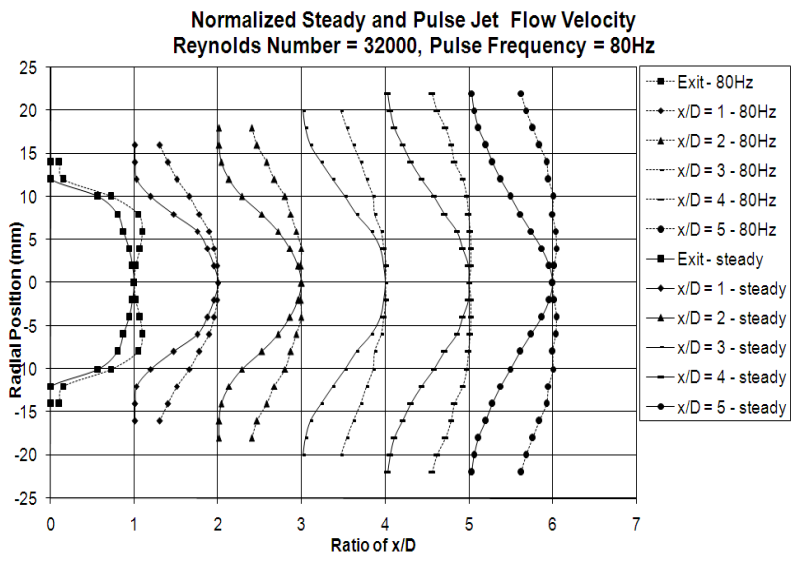

Fig. 4: Comparative radial velocity between steady and pulse jet flow for $\operatorname{Re}=16,000$ and Frequency $=$ $40 \mathrm{~Hz}$

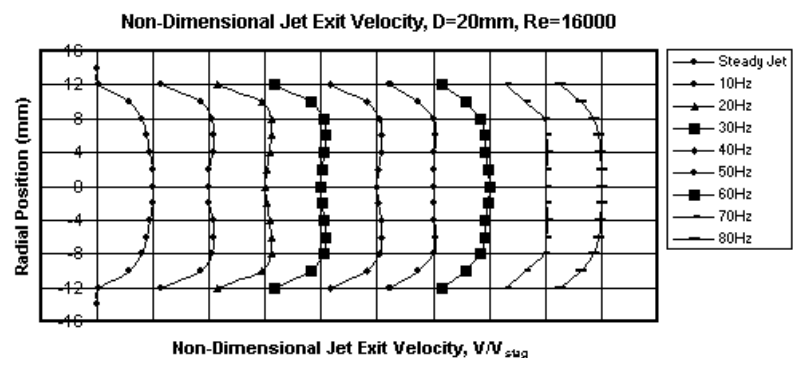

Fig. 5: Jet Exit Velocity Profile for Pulsation frequencies of $10-80 \mathrm{~Hz}$ for $\mathrm{Re}=16000$

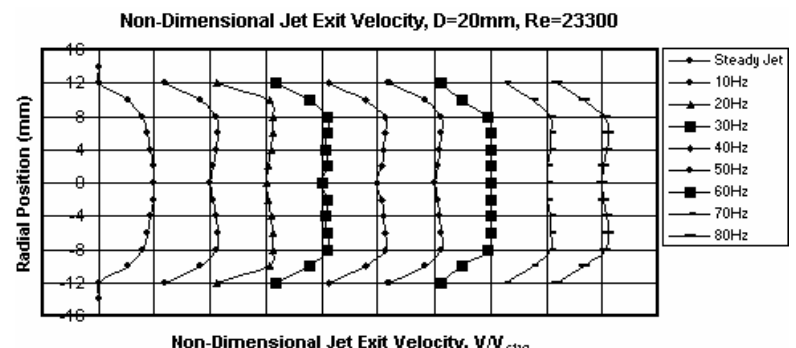

Fig. 6: Jet Exit Velocity Profile for Pulsation frequencies of $10-80 \mathrm{~Hz}$ for $\mathrm{Re}=23300$

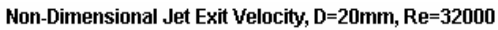

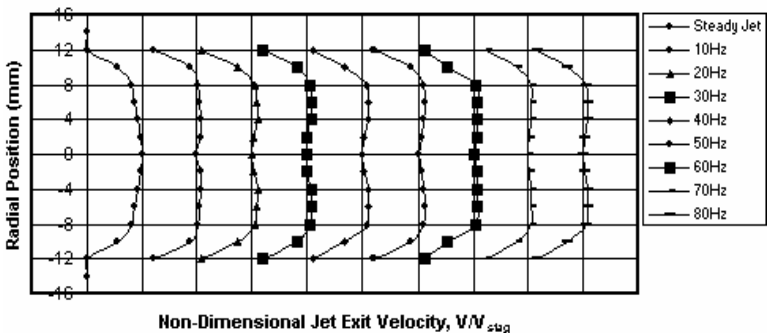

Fig. 7: Jet Exit Velocity Profile for Pulsation frequencies of 10 to $80 \mathrm{~Hz}$ for $\mathrm{Re}=32000$

\section{DISCUSSION}

From the graph in Fig. 4, it can be observed that the velocity of the pulse jet away from the stagnation point is significantly higher that the steady flow at the same localized point. The same trend could be observed for all the Reynolds number and pulse frequencies. This explained why the values of the heat transfer coefficient are higher at these localized point. The velocity profile shows that certain local velocities away from the stagnation point are higher than the velocity at those stagnation points. Since calculations of Reynolds number based on time-averaged centreline velocity does not necessarily mean the mass flow rate is kept constant, hence the Reynolds number is calculated based on the average mass flow rate measurement.

The results have revealed that the unsteadiness associated with the periodic velocity pulsation leads to a variety of vortical structures in the pulsating jet flow field which is agreeable with the results obtained by Jiang et $a l .^{[11]}$ through numerical simulations of the flow and sound fields of a heated axisymmetric pulsating jet simulation. Depending on the pulsating frequency and amplitude, different vortical structures have been observed. 


\section{CONCLUSION}

The purpose of these tests was to evaluate the effect of pulse frequency on the velocity distribution so that the knowledge of the flow field regions of the air exiting the nozzle can be obtained. The results of the experiments show that at higher values of Reynolds, the profile of the flow structure of the air jet exiting from the circular nozzle becomes more scattered. The velocity at the radial distance away from the stagnation point increased significantly especially at higher pulse jet frequency. Heat transfer in the pulse flow mode is complex and dependent on the flow structure of the jet. The significant enhancement of the heat transfer at local distances away from the stagnation point is the result of higher turbulence intensity in this region. The flow profiles of the steady continuous air jet are the same at all three Reynolds Numbers. The stable flow structure created from the experiment is important in order to correctly measure the instantaneous heat transfer.

\section{ACKNOWLEDGEMENT}

The authors express their sincere appreciation for all of the support given by the Government of Malaysia under the Ministry of Science, Technology and Innovation (MOSTI) and Ministry of Higher Education (MOHE).

\section{REFERENCES}

1. Anderson, S.T. and K. Bremhorst, 2002. Investigation of the flow field of a highly heated jet of air. Int. J. Heat Fluid Fl, 23: 205-219. DOI: 10.1016/S0142-727X(01)00150-3

2. Jambunathan, Lai, M.A. Moss and B.L. Button, 1992. A review of heat transfer data for single circular jet impingement. Int. J. Heat Fluid Fl, 13: 106-115. DOI: 10.1016/0142-727X(92)90017-4

3. Kondjoyan, A., F. Peneau and H.C Boisson, 2002. Effect of high free stream turbulence on heat transfer between plates and air flows: A review of existing experimental results. Int. J. Therm. Sci., 41: 1-16. DOI: 10.1016/S1290-0729(01)01299-6
4. Kataoka, K. and M. Suguro, 1987. The effect of surface renewal due to large scale eddies on jet impingement heat transfer. Int. J. Heat Mass Tran, 30: 559-567. http://cat.inist.fr/?aModele=afficheN\&cpsidt=7401956

5. Sailor, D.J., J.R. Daniel and F. Qianli, 1999. Effect of variable duty cycle flow pulsations on heat transfer enhancement for an impinging air jet. Int. J. Heat Fluid Fl, 20: 574-580. DOI: 10.1016/S0142-727X(99)00055-7

6. Mladin, E.C. and D.A. Zumbrunnen, 2000. Alterations to coherent flow structures and heat transfer due to pulsations in an impinging air-jet. Int. J. Therm Sci., 39: 236-248. DOI: 10.1016/S1290-0729(00)00242-8

7. Zumbrunnen, D.A. and M. Aziz, 1993. Convective heat transfer enhancement due to intermittency in an impinging jet. J. Heat Transf., 115: 91-98. DOI: 10.1115/1.2910675

8. Farrington, R.B. and S.D. Claunch, 1994. Infrared imaging of large amplitude, low frequency disturbances on a planar jet. AIAA. J., 32: 317-323. http://cat.inist.fr/?aModele $=$ afficheN\&cpsidt $=3936$ 336

9. Liu, T. and J.P. Sullivan, 1996. Heat transfer and flow structures in an excited circular impinging jet. Int. J. Heat Mass Tran., 39: 3695-3706. DOI: 10.1016/0017-9310(96)00027-0

10. Azevedo, L.F.A., B.W. Webb and M. Queiroz, 1994. Pulsed air jet impingement heat transfer. Exp. Therm. Fluid. Sci., 8: 206-213. DOI: http://direct.bl.uk/bld/PlaceOrder.do?UIN=016503 $149 \&$ ETOC $=$ EN\&from $=$ searchengine

11. Jiang, X, H. Zhao and L. Cao, 2006. Numerical simulations of the flow and sound fields of a heated axisymmetric pulsating jet. Comput. Math. Applied, 51: 643-660.

DOI: 10.1016/j.camwa.2005.03.022 